\section{Se identifica antígeno que podría conducir a una vacuna contra Trypanosoma cruzi}

Los esfuerzos por provocar una buena respuesta inmunitaria contra los parásitos se ven obstaculizados por la poca intensidad de las respuestas inmunitarias específicas contra las moléculas antigénicas de los parásitos durante las fases más tempranas de la infección, lo cual le permite al parásito montar algunos mecanismos de evasión. La activación de linfocitos policlonales es característica general de los procesos infecciosos y las respuestas inmunitarias inespecíficas que dicha activación produce se asocian con procesos de inmunosupresión y de autoinmunidad como los que se observan en la infección por Trypanosoma cruzi, agente causal de la enfermedad de Chagas. En estudios con roedores, la disminución de la respuesta linfocitaria policlonal ha mostrado una correlación con la resistencia a la infección y a la cardiopatía.

Aunque la expansión de poblaciones de linfocitos B y la hipergammaglobulinemia provocada por ella son, al parecer, las responsables de los daños tisulares observados en la trypanosomiasis, la capacidad de evasión del parásito suele ser el resultado, al menos parcialmente, de la liberación de sustancias mitógenas o superantigénicas que inhiben las respuestas específicas del huésped mediante la activación de linfocitos inespecíficos. Un conocimiento a fondo de los mecanismos responsables de estas respuestas linfocitarias policlonales podría señalar el camino hacia el descubrimiento de maneras de neutralizarlas, dejando libre el paso para la producción de una respuesta inmunitaria eficaz contra los parásitos infestantes.

Investigadores del Instituto Pasteur en París han logrado aislar y clonar las proteínas de T. cruzi que ejercen un efecto mitógeno sobre los linfocitos B y han identificado y caracterizado el gen responsable de su producción. Se trata del gen Tc45, cuyo producto proteínico es una variante racémica de la prolina. Es primera vez que se identifica el gen de un aminoácido racémico eucariótico en un parásito, lo cual genera muchos interrogantes sobre las características biológicas de T. cruzi y su interacción con sus huéspedes mamíferos. ¿Cuál podría ser la función de este tipo de actividad enzimática en los procesos biológicos de T. cruzi? Dada la capacidad del parásito de metabolizar la L-prolina y la D-prolina como fuentes únicas de carbono, se especula que las variantes racémicas de la prolina tienen importan- cia en el metabolismo parasitario. Las proteínas que contienen D-aminoácidos son sumamente resistentes a las proteasas de origen eucariótico. Por lo tanto, es posible que el parásito también emplee el mecanismo de la racemización para sintetizar y expresar en su superficie proteínas que contienen D-prolina, adquiriendo de esa forma cierto grado de resistencia a las defensas proteolíticas del huésped. Estos resultados podrían acarrear consecuencias importantes desde el punto de vista de la elaboración de una vacuna contra $T$. cruzi o de medicamentos más eficaces para tratar la infección. (ReinaSan-Martín R, Degrave W, Rougeot C, Cosson A, Chamond N, Cordeiro-da-Silva A, et al. A B-cell mitogen from a pathogenic trypanosome is a eukaryotic proline racemase. Nat Med 2000;6(8):890-897).

\section{Nuevos conocimientos sobre la latencia de Mycobacterium tuberculosis en el organismo}

La mayor parte de las bacterias que infectan el árbol respiratorio se alojan primero en las vías respiratorias superiores, que no son estériles, y ahí esperan a que se debiliten las defensas del huésped en un momento dado para replicarse aceleradamente. En cambio, Trypanosoma cruzi invade los tejidos estériles del pulmón, evadiendo los mecanismos de defensa locales, y establece un nicho dentro del parénquima pulmonar. Posteriormente deja de reproducirse, o se reproduce con mucha más lentitud, mientras espera el momento propicio para proliferar y causar infección sintomática. Durante este estado latente los organismos vivos de $M$. tuberculosis pueden alojarse en el organismo durante decenios sin causar síntoma alguno. Poco se sabe sobre la interacción que se produce durante ese período entre el huésped y el agente patógeno y llegar a entenderla podría darnos la clave para desarrollar nuevas formas de prevenir o combatir la enfermedad.

McKinney et al. han logrado demostrar la importancia de la vía alterna del glioxilato para la supervivencia a largo plazo de $M$. tuberculosis dentro de los tejidos del ratón. Como cualquier otra bacteria, $M$. tuberculosis se tiene que adaptar durante la infección. La vía alterna del glioxilato, que deriva de la isocitratoliasa y la malatosintetasa, les confiere a $M$. tuberculosis y a otras bacterias la capacidad para sintetizar carbohidratos como fuente de energía a partir de ácidos grasos durante el estado latente. Es posible que las bacterias de la fase latente de la enfermedad 
habiten en ambientes granulomatosos con una cantidad reducida de carbohidratos pero con lípidos en abundancia. McKinney et al. también generaron una cepa de $M$. tuberculosis con una mutación en el gen de la isocitratoliasa, estado que inactiva a la bacteria. Las bacterias con la mutación no mostraron la misma capacidad para infectar a los ratones que las bacterias normales. Aunque la mutación no afectó al número de bacterias en la fase inicial de la infección, a partir de la segunda semana hubo una disminución del número de bacterias alojadas en el parénquima pulmonar, aparentemente como resultado de un proceso de eliminación de la forma mutante.

Las investigaciones de McKinney et al. tienen implicaciones para el tratamiento de la tuberculosis y sugiere que existe una clase de genes de $M$. tuberculosis desconocidos previamente que se necesitan para mantener la virulencia durante las fases más tardías de la infección. Este concepto, que ha sido respaldado por el resultado de otros estudios, puede tener consecuencias desde el punto de vista de la vacunación contra la tuberculosis. La actual vacuna a base del bacilo de Calmette-Guérin (BCG) muestra una eficacia que es solo parcial. Puede ser que para lograr la protección a largo plazo se necesite presentarle al sistema inmunitario antígenos bacterianos expresados en las fases más tardías de la infección por M. tuberculosis. De ahí que los estudios sobre cepas que se ven atenuadas en dichas fases, tales como las que han sido aisladas por McKinney et al., podrían llevar a la producción de una vacuna más eficaz contra la tuberculosis. (McKinney, et al. $\mathrm{Na}$ ture 2000;406:735-738; Bishai W. Lipid lunch for persistent pathogen. Nature 2000; 406:683-685.)

\section{¿Por qué varía la absorción de calcio en mujeres sanas perimenopáusicas?}

Los beneficios que puede rendir el calcio dependen no solamente de la cantidad ingerida en la dieta, sino de la capacidad del organismo para absorber este nutriente. Los estudios efectuados hasta el momento se han limitado, en su mayor parte, a medir la ingestión de calcio sin tener en cuenta la cantidad absorbida, que puede variar desde menos de $10 \%$ hasta más de $60 \%$ en mujeres relativamente sanas.

No se conocen bien los factores que explican por qué algunas mujeres absorben mal el calcio mientras que otras lo absorben con gran eficiencia. Se ha demostrado en algunos estudios que factores tales como la edad, las concentraciones de estrógenos y la ingesta habitual de calcio explican solo una mínima parte de la variación observada en la cantidad de calcio absorbida por el organismo. La eficiencia de esta absorción también parece relacionarse in- versamente con la cantidad de calcio ingerida en la dieta. Además, las concentraciones séricas de 25-hidroxivitamina $\mathrm{D}$, el tiempo entre la ingestión por vía oral y la llegada al ciego, y el calcio urinario parecen ser fuentes de variación importantes, según algunos estudios. No obstante, una fracción cuantiosa de la variación individual observada no ha sido explicada aún, especialmente en mujeres sanas.

Wolf et al., de la Universidad de Pittsburgh, Pensilvania, emprendieron un estudio con el fin de explorar otras posibles causas de la variación en la eficiencia de la absorción del calcio. Reunieron una muestra de 142 mujeres sanas pre y perimenopáusicas, a las cuales les hicieron determinaciones del porcentaje de calcio absorbido. También examinaron sus hábitos alimentarios, estilo de vida y concentraciones de hormonas calciotrópoicas, así como la presencia de polimorfismos de los genes de los receptores de la vitamina D. La asociación entre las variables independientes y la absorción de calcio se determinó mediante coeficientes de correlación de Pearson. Se emplearon pruebas $t$ y análisis de la varianza para determinar las medias no ajustadas de las diferencias en la fracción de calcio absorbida según los diferentes genotipos. Un análisis de regresión múltiple por etapas se empleó para determinar qué factores tenían mayor valor predictivo independiente en términos de la absorción de calcio.

Los resultados revelaron una absorción media de $35 \%$ con un recorrido de 17 a $58 \%$. Se encontró una asociación positiva entre el porcentaje de calcio absorbido y el índice de masa corporal $(r=0,22 ; P=$ $0,007)$, ingestión de lípidos en la dieta $(r=0,29 ; P=$ $0,001)$, concentraciones séricas de dihidroxivitamina $\mathrm{D} 1,25\left[1,25(\mathrm{OH})_{2} \mathrm{D}\right](r=0,23 ; P=0,006)$, y concentraciones séricas de hormona paratiroidea $(r=0,21$; $P=0,015)$. La fracción de calcio absorbida mostró una relación inversa con la ingestión total de calcio $(r=-0,18 ; P=0,030)$, fibra $(r=-0,19 ; P=0,028)$, alcohol $(r=-0,14 ; P=0,094)$; con la actividad física $(r=-0,22: P=0,007)$ y con síntomas de estreñimiento $(r=-0,16 ; P=0,059)$. Según el análisis de regresión múltiple por etapas, el consumo de lípidos, de fibra y de alcohol, así como las concentraciones séricas de $1,25(\mathrm{OH})_{2} \mathrm{D}$, son factores predictivos independientes en relación con la absorción de calcio y explican $21,02 \%$ de la variación observada. Las mujeres en el tercil más bajo en términos de la razón de lípidos a fibra en la dieta mostraron una absorción de calcio 19\% inferior a la de las mujeres en el tercil más alto (prueba de tendencia, $P<0,001$ ).

En resumen, las mujeres sanas muestran una amplia variación en el porcentaje del calcio ingerido que absorben. La razón de lípidos a fibra en la dieta parece guardar una relación importante con las diferencias de absorción entre mujeres en la población en general. (Wolf RL, Cauley JA, Baker CE, 
Ferrell RE, Charron M, Caggiula AW, et al. Factors associated with calcium absorption efficiency in pre- and perimenopausal women. Am J Clin Nutr 2000;72(2):466-471).

\section{Idoneidad de los estudios en gemelos para investigar el sistema inmunitario}

Desde fines del siglo XIX, los estudios en pares de gemelos han sido de singular valor en el campo de la biología, la medicina y la psicología. Las investigaciones sobre las enfermedades de tipo autoinmunitario - diabetes mellitus (DM) de tipo juvenil, lupus eritematoso sistémico (LES), artritis reumatoide (AR), esclerosis múltiple (EM), espondilitis anquilosante, enfermedad celíaca, etc.-, que afectan a $5 \%$ de la población y que producen gran morbilidad y mortalidad, constituyen un excelente ejemplo de la utilidad de los estudios en gemelos para estudiar fenómenos relacionados con la inmunidad. Aunque se cree que tanto factores genéticos como ambientales contribuyen a la patogenia de estas afecciones, es tan pronunciado el efecto de los primeros, y se conocen tan poco los genes responsables de la respuesta inmunitaria, que los estudios en gemelos representan la única manera de descartar el papel de factores genéticos en las diferencias inmunológicas observadas.

Según una revisión de los estudios publicados hasta el momento, las pruebas más contundentes de que las enfermedades autoinmunitarias se deben a factores ambientales proceden de estudios en gemelos monocigóticos, puesto que la mayoría de los afectados tienen un gemelo idéntico normal. Hasta la fecha, sin embargo, los estudios en gemelos monocigóticos (siendo uno sano y el otro enfermo) no han servido para identificar ningún factor ambiental específico de importancia crítica en la aparición de las enfermedades autoinmunitarias. Los estudios en gemelos también pueden efectuarse para cuantificar el impacto de factores genéticos en las causas de la enfermedad. Una mayor concordancia en gemelos monocigóticos que en gemelos dicigóticos claramente sugiere que hay factores genéticos de por medio, como se ha observado en el caso de la EM, la $\mathrm{AR}$, la DM con dependencia a la insulina y el LES. La concordancia en gemelos no idénticos es menos de $50 \%$ de la observada en gemelos univitelinos, lo cual sugiere la influencia de muchos genes en la patogenia de esta afecciones. En su conjunto, estos estudios apuntan hacia la presencia de una susceptibilidad genética que facilita la aparición de síntomas, aun cuando factores ambientales ejercen una fuerte influencia causal en la aparición de la enfermedad.

Se ha observado una asociación entre el tipo HLA del complejo mayor de histocompatibilidad
(MHC) y la aparición de síntomas de enfermedad en el caso de muchas enfermedades autoinmunitarias. La contribución relativa del locus del HLA a la aparición de enfermedad puede estimarse mediante una comparación de las tasas de concordancia entre gemelos monocigóticos y dicigóticos. Tales estudios han demostrado que el HLA-B27 se asocia estrechamente con la aparición de artritis reumatoide, pero el valor de estos estudios para investigar el papel de los genes de HLA y de factores ajenos a HLA en el caso de otras enfermedades autoinmunitarias no ha sido debidamente explotado debido, en gran medida, a la escasez de gemelos afectados. También existen otras dificultades. En primer lugar, los gemelos monocigóticos suelen estar expuestos a ambientes más homogéneos, tanto in utero como durante la niñez, lo cual podría llevar a una sobreestimación de la influencia de factores hereditarios. En segundo lugar, los gemelos monocigóticos siempre son del mismo sexo, y muchas enfermedades autoinmunitarias, como la AR, la EM y el LES, son más frecuentes en el sexo femenino. En tercer lugar, los estudios en gemelos se ven limitados por posibles sesgos en la identificación de casos. En estudios de base poblacional, es necesario identificar un gran número de pares de gemelos para poder detectar un número suficiente de gemelos afectados. Por último, la mayor parte de los estudios en gemelos han sido transversales; si se hicieran estudios longitudinales, sería quizá factible detectar mayores tasas de concordancia.

Los gemelos monocigóticos muestran una regulación genética similar en términos de la producción de anticuerpos, aun cuando han sido criados en ambientes separados. Asimismo, factores genéticos pueden regular la cantidad de anticuerpos producidos.

Para sacar un máximo provecho de los estudios en gemelos, es necesario que se produzca una estrecha colaboración entre médicos y otros científicos de los campos de la epidemiología, la inmunología y la genética. Hasta la fecha, los estudios en gemelos solo han proporcionado un entendimiento muy limitado de las respuestas inmunitarias que se asocian con las enfermedades autoinmunitarias, en un número escaso de pares de gemelos y sin análisis prospectivos. No se han explorado algunos temas que se podrían esclarecer mediante estudios en gemelos, entre ellos el efecto de factores genéticos en la gravedad de los síntomas de enfermedad. Si se han de mejorar los estudios basados en gemelos, es imprescindible aumentar el número de pares de gemelos estudiados mediante la creación de un registro de gemelos en la población. Esta medida debe acompañarse de instalaciones centralizadas para el almacenamiento de sueros y monocitos periféricos congelados extraídos de estos individuos, 
con el fin de poder tener acceso a materiales biológicos de personas que nunca han recibido un tratamiento. (Salvetti M, Ristori G, Bomprezzi R, Pozzilli P, Leslie RDG. Twins: mirrors of the immune system. Immunol Today 2000;21(7):309-354).

\section{El factor VIII y el riesgo de trombosis venosa recurrente}

Concentraciones plasmáticas elevadas del factor VIII de la coagulación constituyen un factor de riesgo de sufrir trombosis venosas profundas. En individuos con concentraciones mayores de 150 UI por decilitro, el riesgo es cinco veces mayor que en aquellos cuyas concentraciones son normales, según estudios efectuados en Europa. En pacientes que han sufrido trombosis venosas, la prevalencia de concentraciones elevadas de factor VIII en el suero es de alrededor de $20 \%$. La elevación de las concentraciones se mantiene a lo largo del tiempo, no es atribuible a una reacción propia de la fase aguda, y podría estar asociada con una predisposición genética. Hasta el momento no se ha descubierto el mecanismo responsable de la relación entre el factor VIII y el riesgo de trombosis.

Las trombosis venosas se pueden prevenir mediante la administración profiláctica de anticoagulantes orales, pero estos medicamentos pueden producir hemorragias graves o incluso mortales. La duración óptima de la profilaxis tras la suspensión de los medicamentos anticoagulantes es difícil de calcular, ya que debe sopesarse con el riesgo de hemorragia. En un pequeño estudio retrospectivo se detectó una asociación entre el riesgo de trombosis venosa recurrente y las concentraciones plasmáticas de factor VIII. A la luz de estos resultados, Kyrle et al. efectuaron otros estudio con 360 pacientes que habían tenido un primer episodio espontáneo de trombosis venosa con el fin de estudiar los efectos de una elevación del factor VIII sobre el riesgo de una trombosis venosa recurrente. Los pacientes tuvieron un seguimiento promedio de 30 meses después del episodio inicial. Se excluyó de la muestra a pacientes con episodios recurrentes previos, deficiencia congénita de algún factor de la coagulación, presencia del factor anticoagulante del lupus, hiperhomocisteinemia, cáncer, embarazo o un trastorno que exigiera un tratamiento prolongado a base de anticoagulantes. El resultado de interés fue un segundo episodio sintomático de trombosis venosa.

Tuvieron trombosis venosa recurrente 38 de los 360 pacientes estudiados (10,6\%). Estos pacientes mostraron concentraciones medias ( \pm una desviación estándar) del factor VIII más elevadas que los que no tuvieron un episodio recurrente (182 \pm 66 frente a $157 \pm 54$ UI por decilitro; $P=0,009$ ). El riesgo relativo de una trombosis venosa recurrente fue de 1,08 (IC95\%: 1,04 a 1,12; $P<0,001$ ) por cada aumento de 10 UI de las concentraciones plasmáticas del factor VIII. En pacientes cuyas concentraciones superaban las de $90 \%$ de la población estudiada, la frecuencia de recurrencias al cabo de dos años fue de $37 \%$, en comparación con $5 \%$ en pacientes con concentraciones más bajas $(P<0,001)$. En pacientes con concentraciones plasmáticas de factor VIII mayores que las de $90 \%$ de la población estudiada, el riesgo relativo de una recurrencia fue de 6,7 (IC95\%: 3,0 a 14,8) después de hacer ajustes por edad, sexo, presencia o ausencia de factor $\mathrm{V}$ de Leiden o de la mutación del G20210A de la protrombina, y la duración de la anticoagulación.

Se puede deducir a partir de estos resultados que los individuos cuyas concentraciones plasmáticas de factor VIII están elevadas tienen un mayor riesgo de sufrir una trombosis venosa profunda. (Kyrle PA, Minar E, Hirschl M, Bialonczyk C, Stain M, Schneider B, et al. High plasma levels of factor VIII and the risk of recurrent venous thromboembolism. N Engl J Med 2000;343:457-462).

\section{¿Por qué les nacen pocos niños de bajo peso a las mujeres mexicanoestadounidenses?}

La incidencia de bajo peso al nacer es relativamente baja en los hijos de mujeres mexicanoestadounidenses, pese a las condiciones económicas adversas que estas mujeres suelen enfrentar. Las causas de esta paradoja no se han explorado, aunque son varios los investigadores que han documentado y señalado su presencia. Al parecer, las mujeres mexicanoestadounidenses y sus hijos están protegidos por uno o varios factores desconocidos cuyo esclarecimiento podría ayudar a la comunidad científica a entender más a fondo las causes del bajo peso al nacer en general.

Hay dos tipos de neonatos con un peso inferior al normal ( $<2500 \mathrm{~g})$ : los que nacen a término y los que nacen prematuramente. Una tasa reducida de bajo peso al nacer implica que los niños que nacen a término pesan más de lo esperado, que hay menos partos prematuros, o ambas cosas. En el caso de la población mexicanoestadounidense, aún no se ha efectuado ningún análisis de la distribución ponderal de los neonatos nacidos a término y las tasas de prematuridad que han sido publicadas han sido contradictorias: algunos estudios han revelado tasas favorables de prematuridad, mientras que las estadísticas vitales apuntan hacia la presencia de una tasa de prematuridad más elevada en esta población.

Con el fin de arrojar luz sobre esta situación, un grupo de investigadores examinó datos obtenidos de certificados de nacimiento de los niños que 
nacieron en 1994 de madres mexicanoestadounidenses y de madres blancas de origen no hispano. El objetivo era evaluar los componentes del bajo peso al nacer en la población mexicanoestadounidense mediante una comparación de la distribución ponderal de niños nacidos a término y de las edades gestacionales de neonatos mexicanoestadounidenses y de niños blancos de origen no hispano. Los investigadores primero calcularon las tasas de bajo peso al nacer, peso excesivo al nacer ( $>4500 \mathrm{~g})$ y peso medio al nacer, así como las desviaciones estándar de cada población. También evaluaron la posibilidad de errores en el cálculo de la edad gestacional anotado en los registros de estadísticas vitales.

Según los resultados, las menores tasas de bajo peso al nacer en la población mexicanoestadounidense $(5,8 \%)$, al compararse con la población blanca no hispana $(6,1 \%)$, se deben a que en la primera nacieron menos niños prematuros y pequeños $(3,4$ frente a $3,8 \%$ ). Sin embargo, el peso medio al nacer de los niños mexicanoestadounidenses (3 $343 \mathrm{~g}$ ) fue inferior al de los niños blancos no hispanos (3 $393 \mathrm{~g}$ ). Este resultado confirma que el peso medio al nacer y el peso bajo al nacer son fenómenos independientes. También se detectó una mayor tasa general de prematuridad en la población mexicanoestadounidense $(10,6 \%)$ que en la población blanca de origen no hispano $(9,3 \%)$. Según infieren los autores, este hallazgo se atribuye a errores en la edad gestacional anotada en los registros estadísticos, como sugiere la distribución claramente bimodal que muestra el peso al nacer en niños mexicanoestadounidenses de poca edad gestacional. Se concluye que los estudios sobre la paradoja del peso al nacer en niños mexicanoestadounidenses deben concentrarse en la edad gestacional más que en el peso al nacer. (Buekens P, Notzon F, Kotelchuck M, Wilcox A. Why do Mexican Americans give birth to few low-birthweight infants? Am J Epidemiol 2000; 152(4):347-351).

\section{Factores que suscitan episodios primarios y recurrentes de depresión grave en la mujer}

La depresión grave es un trastorno frecuente cuyas causas son sumamente complejas. Es evidente que entre los factores causales figuran las experiencias vitales dolorosas, así como diátesis de origen genético de más larga duración, pero es muy poco lo que se sabe sobre la forma en que estos factores ejercen su influencia a lo largo del tiempo. Kraepelin fue el primero en postular que los factores adversos de tipo psicosocial desempeñan un papel muy importante en un primer episodio de depresión grave y que los episodios recurrentes suelen ser más autónomos y guardar menos relación con causas exógenas o ambientales. Posteriormente, otros investigadores han atribuido esta tendencia a un proceso de sensibilización frente a la depresión. Esta hipótesis, que se ha denominado la hipótesis de la ignición (kindling hypothesis), puede expresarse en términos de actividad mental: La vulnerabilidad a episodios depresivos recurrentes se ve determinada por un riesgo aumentado de caer en patrones negativos de procesamiento de la información ... un aumento de la tendencia a depender de estos patrones de procesamiento facilita su futura activación por estímulos cada vez más pequeños. Aunque en los siete estudios publicados en inglés se ha encontrado que la proporción de personas en quienes una situación adversa parece haber desencadenado el episodio depresivo fue mayor en los casos de un primer episodio que en el de episodios recurrentes, un grupo de investigadores ha puesto en tela de juicio la confiabilidad de estos estudios sobre la base de sus posibles limitaciones metodológicas. Dichos investigadores formaron una muestra de pares de gemelas $(n=2395)$ [un total 97515 meses-persona y 1380 episodios de depresión mayor] que fueron entrevistadas durante un período de 9 años. Aplicaron un análisis de supervivencia en diferentes momentos, un modelo de riesgos proporcionales y análisis de regresión paso a paso a fin de examinar la interacción entre la exposición a situaciones adversas y el número de episodios depresivos anteriores, para poder pronosticar episodios de depresión grave.

En las mujeres que habían sufrido de cero a nueve episodios depresivos anteriores, se observó una relación inversa a lo largo del tiempo entre la presencia de una experiencia adversa y la aparición de un nuevo episodio depresivo. Esta relación inversa dejó de observarse después del noveno episodio de depresión grave, y los resultados se mantuvieron aun después de introducir en el modelo la gravedad de la experiencia adversa y los indicadores del riesgo genético, y después de limitar las experiencias adversas a las que tenían carácter independiente.

Cabe afirmar, a la luz de estos resultados, que la asociación entre el número de episodios depresivos anteriores y el efecto desencadenante de experiencias adversas en la aparición de dichos episodios es causal y bifásica. Esta asociación causal va menguando a lo largo del tiempo hasta que se llega a un umbral (nueve episodios, según este estudio) más allá del cual el cerebro ya no parece sufrir ninguna sensibilización adicional al estado depresivo. (Kendler KS, Thornton LM, Gardner CO. Stressful life events and previous episodes in the etiology of major depression in women: an evaluation of the "kindling" hypothesis. Am J Psychiatr 2000;157: 1243-1251). 